\title{
OSSIFICATION OF OVARIAN CYST: A RARE CASE REPORT
}

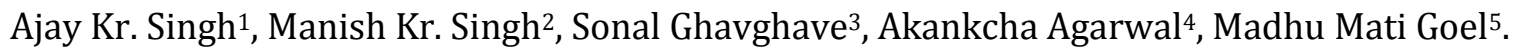

1. Assistant Professor. Department of Pathology. King George's Medical University.

2. Post Graduate, Department of Pathology. King George's Medical University.

3. Post Graduate, Department of Pathology. King George's Medical University.

4. Post Graduate, Department of Pathology. King George's Medical University.

5. Professor, Department of Pathology. King George's Medical University.

\section{CORRESPONDING AUTHOR:}

Dr. Ajay Kr. Singh,

King George's Medical University Lucknow,

UP, India- 226003.

E-mail: drajaysingh007@gmail.com

\section{HOW TO CITE THIS ARTICLE:}

Ajay Kr. Singh, Manish Kr. Singh, Sonal Ghavghave, Akankcha Agarwal, Madhu Mati Goel. "Ossification of ovarian cyst: a rare case report". Journal of Evolution of Medical and Dental Sciences 2013; Vol2, Issue 25, June 24; Page: 4523-4527.

ABSTRACT: Ossification in ovarian cyst is an exclusively rare entity. The most common findings associated with ovarian ossification is dermoid cyst, osseous metaplasia in stroma rich in serous or mucinous neoplasm and ossification of chocolate cyst. Here the author reports a case of incidental finding of ossification in the chocolate cyst of resected ovary in 42 year old female, who had gone for total abdominal hysterectomy with bilateral salpingo-oophorectomy for the provisional diagnosis of postmenopausal bleeding. The clinical significance of ossified ovarian cyst is that they mimic malignant lesion but they can treat conservatively with close follow-up apart from the malignant lesion which always treat surgically.

KEYWORDS: Ossification, Ovarian cyst, Endometriosis.

INTRODUCTION: Ossification in ovarian cyst, as an exclusive finding, and not much common entity. The most common underlying finding associated with this is dermoid cyst or teratoma of the ovary which also have other additional features like hair, cartilage and muscle etc. also found within the tumor [1]. Other causes of such ossification include osseous metaplasia in stroma rich serous or mucinous neoplasm. Ossifying chocolate cyst is may be misdiagnosed as teratoma, or calcified ovarian tumour on sonography. The ossified chocolate cyst is not a indication of surgery but other remaining lesion treating mainly by surgical intervention. This type of ambiguity which is came after sonography remove only by histopathological examination with clinical correlation.

CASE REPORTS : A 42 yrs aged female $\left(\mathrm{P}_{4+3}\right.$ and younger child 14 years old) presented with lower abdominal pain with discharge per vaginum for last 2 years and history of irregular menstruation for last 1 year. Following this, provisional diagnosis of postmenopausal bleeding and total abdominal hysterectomy with bilateral salpingo-oophorectomy was done.

Gross examination reveals resected uterus \& cervix measuring $7.5 \times 5.5 \times 2 \mathrm{~cm}$ in size. Cut surface of both was unremarkable and posterior uterine wall thickness was measuring $2.0 \mathrm{~cm}$. 
Right ovary was measuring 3x2x1.5 cm with cut surface having a hemorrhagic cyst measuring $2 \mathrm{~cm}$ in size. Right fallopian tube was measuring $7 \times 0.5 \mathrm{~cm}$ with grossly unremarkable. Left ovary was measuring $4 \times 3.5 \times 2.5 \mathrm{~cm}$ in size and cut surface have a bony cyst of $3 \mathrm{~cm}$ in diameter and filled with hemorrhagic material. Wall thickness of cyst wall varies from 0.2 to $0.4 \mathrm{~cm}$. Left fallopian tube was measuring $6.5 \times 0.5 \mathrm{~cm}$. Microscopic examination showed uterus lined by proliferative endometrium with insignificant underlying myometrium. Cervix examination revealed chronic cervicitis in the form of diffuse inflammatory infiltrate in to the cervical stroma. Examination of right ovary showed hemorrhagic corpus luteal cyst. While both fallopian tubes had normal histology, microscopic examination of left ovary was striking. Multiple sections of left ovary showed a cystic structure, and ovarian wall was totally replaced by areas of ossification and calcification.

Following these observations, different etiologies for such ossification in ovary were find out, which includes dermoid cyst, osseous metaplasia in stroma rich neoplasm of ovary and chocolate cyst of ovary. With the help of gross features and excluding other etiologies, a diagnosis of ossification in chocolate cyst was made.

DISCUSSION: Bone formation in the ovary with exception of developing in setting of mature cystic teratoma is exceedingly rare [1]. Pathological calcification are classified as either metastatic (associated with hypercalcemia) or dystrophic (associated with hormonal calcemia) [2]. Traditionally the calcification in neoplasm have been considered to be dystrophic form of secondary to degeneration of either or in associated with areas of necrosis [3].

The most widely accepted theory regarding the pathogenesis of calcification postulate that calcification are due to calcium deposition in areas of cellular degeneration associated with either an infection process, such as malakoplakia or with ischemic changes. Calcification have been described in various neoplasm associated with hormone production including duodenal Somatostatinoma, carcinoid tumour, prolactinoma, calcifying Sertoli cell tumour and gonadoblastoma [3].

In benign lesion, the endometrium of patient receiving Enovid (combined contraceptive pills) and clomiphene citrate for contraception are the possible cause of calcification. In nonneoplastic lesion of ovary like endometrioma, previous torsion with subsequent infarction of ovary can explain the bone formation [4,5]. Few no. of cases in which ossification was seen in the ovary, an associated endometriosis or chronic inflammation was present. Calcified cavernous hemangioma of ovary was also presenting as differential diagnosis [6].

In benign and malignant tumour, it is likely that multiple mechanisms are involved in the pathogenesis of calcification because calcification are seen in areas of necrosis and in tumours with degenerative changes.

In one study the differential diagnosis of a calcified adnexal mass usually include a degenerative uterine or intra-ligamentous myoma of an ovarian tumour such as fibrothecoma, Brenner tumour and mature or immature teratoma [6]. Secondary calcification occur in hyalinized tissue in about $4 \%$ of uterine myoma and usually dense and amorphous.

In a study of ossification luteinized thecoma of ovary with endometrial adenocarcinoma said that Luteinized thecoma undergone massive ossification converting the ovary in to a bone. True bone formation in ovarian tumour is rare. Osseous metaplasia could be the cause in this setting [7]. 
Osseous metaplasia has been documented in well differentiated Sertoli, Leydig cell tumours, mucinous cystadenoma, fibromas and serous papillary cystadenocarcinoma [8,9]. The cause of bone formation may be hyalinization, dystrophic calcification and subsequent osseous metaplasia. Another theory postulated by some author that the tumour may produce bone forming factor like transforming growth factor $b$ or bone morphogenetic protein (BMP) causing metaplastic transformation of the undifferentiated mesenchymal stromal stem cell in osteoblasts [7]. BMP are a family of growth factors regulating a wide variety of biological processes like bone formation and psammoma body formation in ovarian tumours.

Conclusion is that bone formation in ovarian tumours or benign ovarian cyst is probably due to interplay of various factor that they are not completely understood. In our case the cause of bone formation was probably due to old endometriosis with torsion and subsequent infarction. Endometriosis with ossification mainly treated conservatively with close follow up, and may be adequate in patient with a history of endometriosis. The patient with this type of ossified ovarian mass wish to preserve their fertility, while ossified malignant lesions is always treated surgically.

\section{REFERENCES:}

1. Shaco LR, Lazer T, Piura B, Wiznitzer A. Ovarian ossification associated with endometriosis. Clin Exp Obstel Gynecol.2007; 34(2):113-4.

2. Clement PB, Cooney TP. Idiopathic multifocal calcification of the ovarian stroma. Arch Pathol Lab Med. 1992; 116(2):204-5.

3. Silva EG, Deavers MT, Parlow AF, Gershenson DM, Malpica A. Calfications in ovary and endometrium and their neoplasms. Mod Pathol 2003; 16(3):219-222.

4. Su WH, Wang PH, Chang SP. Ovarian stone. A case report. J Reprod Med 2002; 47(4):329-31.

5. Kennedy LA, Pinckney LE, Curranino G, Votteler TP. Amputated calcified ovaries in children. Radiology 1981; 141(1):83-6.

6. Kim YM, Rha SE, Oh SN, Lee YJ, Jung ES, Byun JY. Ovarian cavernous hemangioma presenting as a heavily calcified adnexal mass. Br j Radiol. 2008; 82(971):e269-71.

7. Pervatikar SK, Rao R, Dinesh US. Ossifying luteinized thecoma of the ovary with endometrial adenocarcinoma. Indian j Pathol Microbiol 2009; 52(2):222-224.

8. Okada S, Ohaki Y, Inoue K, Kawamura T, Hayashi T, Kato T, Kumazaki T. Calcification in mucinous and serous cystic ovarian tumours. J Nihon Med Sch.2005; 72(1):29-33.

9. Zahn CM, Kendall BS. Heterotopic bone in the ovary associated with a mucinous cystadenoma. Mil Med.2001; 166(10):915-7. 


\section{CASE REPORT}

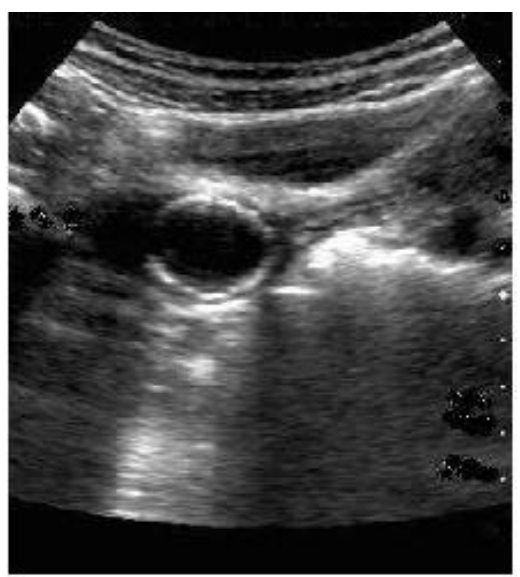

Fig 1. USG of left ovary shows ossified ovarian cyst.

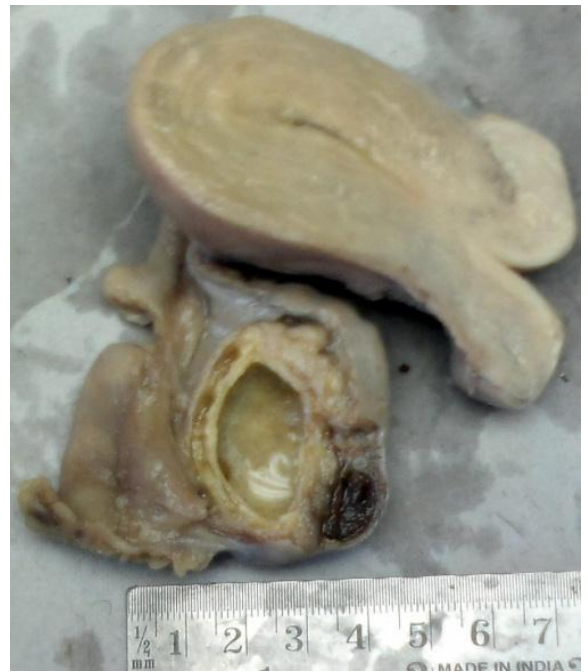

Fig 2. Gross specimen show ossified ovarian cyst with haemorrhagic areas with uterus.

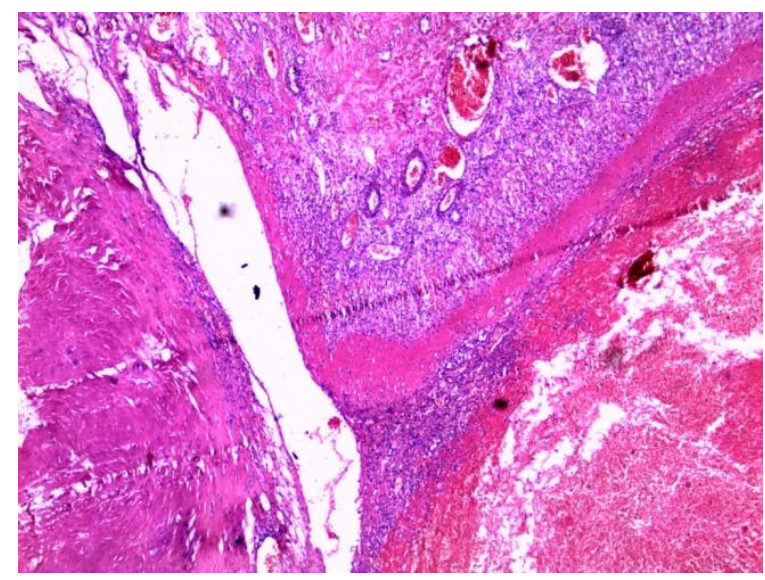

Fig3. Hematoxylin \& Eosin (10x) stain- Histopathology section of ovarian cyst show area of calcified with focal ovarian tissue. 


\section{CASE REPORT}

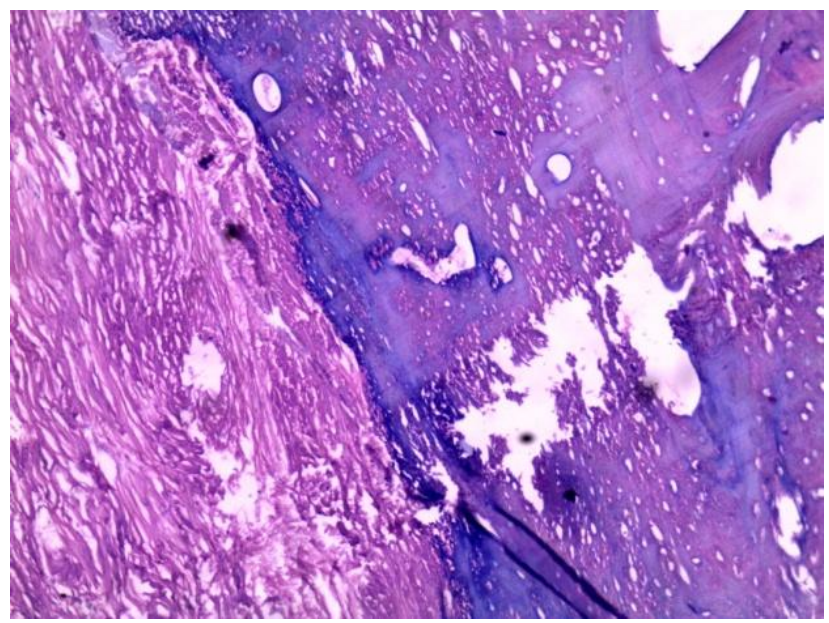

Fig 4. Hematoxylin \& Eosin (40x) stain-Section of ovarian cyst show ossified ovarian cyst with lamellar bone formation with fibrous wall. 